\title{
Eventos QuÂnticos E Reducionismo CaUsal
}

\author{
Osvaldo Pessoa JR.
}

\begin{abstract}
This paper is the first step in an investigation of whether microscopic events can be reduced to a mereological composition of elementary events, especially in biological systems. The hypothesis is made that, between events in which quanta are exchanged, there is causal flow, but strictly speaking no events take place. A causal event is characterized by the possibility of an intervention or manipulation. Thus, three types of quantum mechanical events may be found: (1) detection of a quantum of energy; (2) confinement by an apparatus in a Glauber coherent state; (3) null result measurement (without exchange of quanta). The paper explores these three types of elementary causal events, e sets forth as the next step the investigation of the causal events involved in the action of a molecular motor.
\end{abstract}

Keywords: Quantum mechanics; causation; event; reductionism; molecular motor.

\section{Reducionismo causal}

Muitas discussões em filosofia da biologia envolvem o conceito de "causalidade", como as noções de causas remotas e próximas (Mayr, 1961; Caponi, 2009), causas individuais e populacionais (Bentonet al. 2006), seleção natural multinível (Wilson 1997) e causalidade circular (Westerhoff \& Hofmeyr 2005). Em filosofia da mente, soma-se a questão da causalidade do agente na tomada de decisões (Libet 1999).

Uma estratégia metodológica para abordar essas questões é tentar reduzir a causalidade macroscópica, presente nessas discussões, a eventos causais mais elementares. Tal metodologia filosófica reducionista será adotada neste trabalho, onde exploramos a base de uma descrição bottom-up (de baixo para cima) da causalidade a partir do nível quântico e da transição para a escala nanoscópica das flutuações térmicas. A adoção de tal metodologia, porém, não significa que as implicações ontológicas sejam necessariamente reducionistas, conforme veremos.

Duas questões correlatas serão investigadas neste trabalho. (I) Primeiro, se os eventos quânticos (troca de quanta) podem ser considerados eventos causais elementares. (II) Segundo, se esses "átomos causais" poderiam ser os elementos a partir dos quais todos os processos causais entre eventos macroscópicos seriam constituídos.

A primeira pergunta pode ser respondida afirmativamente, desde que se reserve lugar para processos causais quânticos contínuos (que se dão entre os eventos de troca de quanta), que seriam a "cola" que liga os eventos elementares (fazendo referência à expressão "cement of the universe", de Hume 1740).

Principia 17(3): 365-381 (2013).

Published by NEL — Epistemology and Logic Research Group, Federal University of Santa Catarina (UFSC), Brazil. 
A segunda questão, da viabilidade do reducionismo causal, será deixada em aberto. Vale notar que esta questão envolve a possibilidade de redução entre eventos (de eventos macroscópicos a eventos elementares), e não entre entes materiais (como no clássico exemplo de se um gás se reduz às suas moléculas constituintes). O que faremos na seção 12 do presente artigo é apenas indicar os tipos de eventos que o projeto reducionista causal teria que descrever para explicar causalmente um processo biológico bastante simples, que é o motor molecular.

\section{Eventos causais vs. determinismo}

Iniciemos destacando duas noções fundamentais envolvidas na noção cotidiana de "causalidade".

(i) A primeira é que uma intervenção ou manipulação por parte de uma pessoa (ou outro animal) pode alterar o curso dos acontecimentos (Pearl 2000, p.22-9, 346-50; Woodward 2008). Isso pode ser estendido para o mundo inanimado por meio da noção de evento, como a erupção de um vulcão: apesar de este evento não poder ser manipulado por seres humanos, pode-se conceber que o evento poderia não ter ocorrido.

(ii) Uma segunda noção usualmente associada ao termo "causalidade" é que um estado de coisas no tempo presente determinaria univocamente um estado futuro (ou não, numa situação de quebra do determinismo). Nesta acepção, a causalidade é concebida como o escoamento de algum fluido, como um "processo causal" contínuo, concebível mesmo que não haja a ocorrência de eventos especiais sujeitos à manipulação.

Neste trabalho, investigaremos justamente a hipótese de que, abaixo da escala quântica ou entre eventos quânticos, ocorre uma espécie de "escoamento causal", mas que neste domínio não aconteceria qualquer "evento" propriamente dito. Um evento é entendido (de maneira pouco precisa) como um processo de curta duração temporal, bem localizado espacialmente, que se destaca de seu ambiente temporal e espacial. Qualquer intervenção humana em um processo causal será considerada um evento.

Um exemplo de evento elementar seria a absorção de um quantum em uma medição, e estaria relacionado à passagem da física quântica para a física clássica. Com esta suposição, responde-se afirmativamente à questão (I) da seção anterior, mas veremos que há pelo menos três tipos diferentes de eventos causais em experimentos quânticos. Aceitando-se a tese (I) (mesmo que com qualificações), a tese (II) esboçada acima indicaria que todos os processos causais no mundo cotidiano envolveriam eventos macroscópicos que poderiam ser considerados uma composição mereológica de eventos quânticos, como os mencionados em (I). Um ato de

Principia 17(3): 365-381 (2013). 
manipulação de uma causa, por parte de um ser vivo, seria um desses tais eventos macroscópicos. Processos em células biológicas envolveriam eventos "mesoscópicos" que também seriam uma composição de eventos quânticos.

Tal composição de eventos causais mais elementares, formando um evento mais macroscópico, deve ser entendida sincronicamente, ou seja, em um mesmo instante de tempo. John Stuart Mill (1843, livro III, cap. VI) traçou a importante distinção entre composição "homopática" e "heteropática" de causas, o que hoje chamamos respectivamente de "linear" e "não linear". Esta, porém, é uma relação entre, por um lado, o conjunto de causas, e por outro, o efeito (que ocorrem em diferentes instantes do tempo). Por exemplo, se a mistura de uma solução azul com uma solução transparente for uma composição homopática, o produto (o efeito) terá uma cor azul clara, ponderada pelas quantidades de cada uma das soluções iniciais (as causas). Neste artigo, enfocamos apenas o conjunto de causas em um instante de tempo (e não os respectivos efeitos), inquirindo se um evento macroscópico pode ser reduzido a uma composição de eventos nanoscópicos (o que poderia se dar de maneira linear ou não linear).

\section{Três tipos de eventos quânticos}

Uma questão que tem surgido nas últimas décadas na biologia, com relação à noção de causalidade, é se há diferentes níveis ou escalas em que atuam distintas relações causais, de maneira irredutível (ontologia emergentista) (Noble 2012), ou se uma relação macroscópica de causalidade pode sempre ser reduzida a relações causais mais microscópicas (ontologia reducionista).

Ambas as abordagens - a causalidade multiníveis e a reducionista - têm que resolver um problema adicional, que é se há um escala microscópica fundamental em que ocorre a causalidade (quer ela sirva para reduzir a causalidade de níveis superiores ou não), ou se a relação de causalidade ocorre para escalas sucessivamente menores, ad infinitum, como na visão de mundo de Leibniz (1902, p.194-6), com seus animalcula.

Neste trabalho, irei supor que há uma escala fundamental em que ocorrem os "eventos" mais simples que são ligados por processos causais, e que esta é a escala que marca a passagem da física quântica para a física clássica, algo entre 0,1 e 1 nanômetro (onde $1 \mathrm{~nm}$ é um bilionésimo de metro, ou $10^{-9} \mathrm{~m}$ ). Esta passagem está ligada também à presença de "flutuações térmicas" que ocorrem de maneira estocástica nas moléculas (que giram, vibram e contorcem) e no ambiente ao redor (que transmitem energia de translação, como no movimento browniano).

Iremos adotar uma interpretação "objetivista” da teoria quântica, segundo a qual os eventos quânticos ocorrem mesmo sem a presença de um aparelho de medição e 
de um ser humano consciente (ver Pessoa 2007). Segundo a interpretação adotada, na ausência de um aparelho de medição, a transição para um comportamento clássico seria condicionado pela presença de um ambiente ruidoso (ver discussão sobre a "decoerência", na seção 5).

Examinando experimentos quânticos, encontramos que há prima facie três processos distintos aos quais se pode aplicar a noção de "causação como manipulação", e também a noção de evento: (1) a deteç̧ão de um quantum de energia; (2) o confinamento de um sistema quântico; (3) medições de resultado nulo.

(1) A detecção de um quantum de energia por parte de um aparelho de medição é um evento que é amplificado macroscopicamente, sendo um exemplo de transição do mundo quântico para o clássico, e constituindo um processo "irreversível". Interpretações realistas da teoria quântica descrevem este processo como envolvendo um "colapso" de uma onda quântica, ou a transição de uma potencialidade quântica para um ato clássico. As visões objetivistas teorizam que um processo semelhante ocorra na natureza sem a presença de um aparelho de medição em um estado "metaestável", mas sim na presença de um ambiente com flutuações térmicas, associado à decoerência induzida pelo ambiente.

(2) Um segundo tipo de causalidade associado à manipulação é a intervenção macroscópica em sistemas quânticos reversíveis, como a reflexão de um feixe de luz por um espelho, em que não se extrai informação a respeito do sistema quântico, mas (por assim dizer) altera-se a informação associada ao sistema quântico (de maneira que possa ser regatada posteriormente). Neste caso, o equipamento macroscópico "confina" o sistema quântico sem dissipação (de maneira "unitária", como se diz). A este segundo tipo de evento causal chamarei de confinamento. $\mathrm{O}$ ato de confinamento de um sistema quântico pode ser considerado um "evento" macroscópico, redutível à troca de quanta entre aparelho e sistema quântico, sem amplificação. Na seção 7 veremos que uma propriedade essencial de tais equipamentos macroscópicos é serem descritos como um estado quântico com "coerência de Glauber".

(3) Há um outro tipo de confinamento, envolvendo um evento causal manipulável, que é a medição de resultado nulo. Neste caso, não há troca líquida de quanta. Ele será exemplificado pelo interferômetro de Elitzur-Vaidman (seção 10).

A causalidade por confinamento (tipo 2 ) se aproxima da noção de "restrição das partes pelo todo" defendida por alguns filósofos da biologia. Um exemplo é o efeito de restrição provocado pela membrana celular nas reações químicas que ocorrem no interior da célula. Alguns filósofos associam esse tipo de causalidade a uma causa formal (no sentido aristotélico), atuando de um nível superior para um inferior (topdown), como uma "condição de contorno" (Polanyi 1968; El-Hani \& Queiroz 2005). 


\section{Experimento da dupla fenda}

Para introduzir alguns conceitos básicos de física quântica, associados ao evento de tipo (1), partiremos do experimento da dupla fenda, como é usual em textos didáticos e de divulgação (ver Pessoa Jr., 2006, cap. I).

Na Fig. 1 representa-se o experimento da dupla fenda para elétrons, ou sua versão para a luz. Os elétrons passam por uma fenda colimadora e depois por duas fendas, resultando em um padrão de claros e escuros chamado "franjas de interferência". Para explicar essas franjas, é preciso supor que os elétrons (ou a luz) se propagam como ondas distribuídas no espaço, como os círculos indicados na figura. As regiões escuras das franjas são regiões em que as ondas vindas de uma fenda cancelam as ondas vindas de outra (interferência destrutiva).

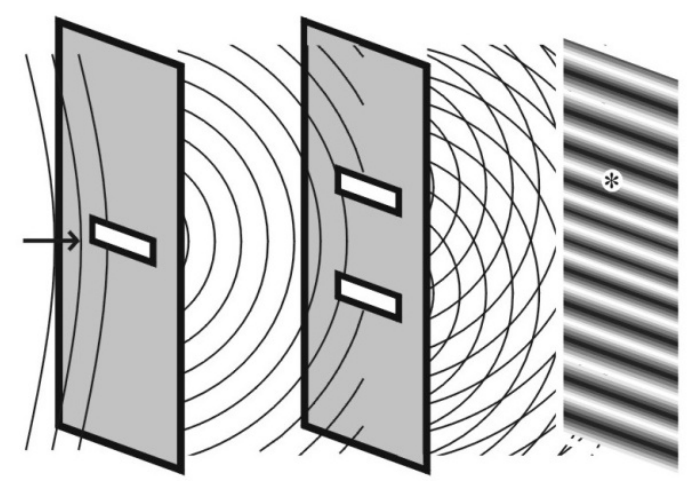

Figura 1: Experimento da dupla fenda, para elétrons ou luz.

Na Fig. 1, representa-se com um asterisco a incidência na tela detectora de um elétron único ou, no caso da luz, de um "fóton". Na verdade, as faixas luminosas do detector são formadas pelo acúmulo, um a um, de tais "quanta". Neste caso, a medição envolve a transferência de um pacote (ou quantum) de energia bem definida, localizada de maneira pontual, do campo eletrônico (ou luminoso) para a tela detectora.

\section{Quantum de causalidade}

O aparecimento do ponto na tela detectora é um exemplo da transição causal de tipo (1), marcada pelo surgimento de um evento macroscópico (o ponto na tela) a partir da interação de um campo eletrônico ou luminoso (ou de outro tipo, conforme o experimento) e o detector. Neste caso, o estado físico do detector é especial: ele é um sistema de muitos corpos (ou seja, muitíssimas moléculas) que se encontra em um

Principia 17(3): 365-381 (2013). 
estado "metaestável", o que o torna extremamente sensível a qualquer perturbação. A detecção de um quantum envolve amplificação de energia, de maneira que é preciso fornecer energia ao sistema, na forma de uma bateria (em fotomultiplicadoras), trabalho mecânico (em câmaras de nuvem) ou processos químicos (no caso de uma chapa fotográfica).

O processo de medição na física quântica é um assunto bastante controvertido, e certamente há questões ainda não resolvidas em sua descrição (ver Pessoa Jr. 2006, cap. XXXI). Em poucas palavras, não há uma descrição teórica satisfatória para o surgimento do evento quântico (o ponto na tela) a partir das leis lineares fundamentais da mecânica quântica. Um avanço foi feito com a noção de "decoerência induzida pelo ambiente". Neste processo, a "coerência" da onda quântica (na Fig. 1, representada pelos círculos que saem de cada fenda, que mantêm o mesmo comprimento de onda e a mesma fase) seria quebrada pela interação com as flutuações aleatórias vindas do ambiente circundante, no caso os elétrons da tela detectora.

Uma razão da importância da noção de decoerência é que ela abre caminho para que se entenda o processo de "colapso da onda quântica" (que descreveria a redução do estado quântico espalhado no espaço, antes da detecção, para o estado bem localizado após a detecção, nos casos em que o sistema quântico não é destruído ou absorvido) de maneira objetiva, sem a necessidade de haver um ser humano consciente observando o experimento. Isso é feito atribuindo-se ao ambiente um papel essencial na decoerência do sistema quântico. A teoria da decoerência fornece apenas uma descrição estatística do surgimento dos eventos individuais de deteç̧ão, de maneira que ele não resolve o problema do colapso da onda individual (ver Pessoa Jr. 1998; Schlosshauer 2004). Apesar de ainda faltar uma descrição teórica do elemento essencial na passagem da decoerência para o colapso (o chamado "problema da medição"), iremos supor que tal passagem de fato ocorre corriqueiramente, em nível molecular, por exemplo na "quebra de simetria" da passagem do estado de superposição de dois autoestados quirais (por exemplo da molécula de sacarose) ou para a molécula no estado levógiro, ou para a molécula no estado dextrógiro (Anderson 1972; Primas 1990).

A formação de um evento de detecção será considerada um processo causal elementar. Era o que Niels Bohr (1934, p.54) chamava "coordenação espaço-temporal". Tal processo envolve um conjunto de condições, que inclui a presença do campo quântico (eletrônico, luminoso, etc.), do detector no estado metaestável apropriado, e da junção espacial dos dois sistemas. No caso da quebra de simetria de uma molécula (como a sacarose), as condições envolvem a molécula em estado de superposição e seu contato com um meio ambiente com flutuações térmicas. Um traço que caracteriza este processo é a irreversibilidade, ou seja, o fato de que, na prática, não se pode desfazer a formação do evento, que se torna um "registro macroscópico" estável. A natureza desta irreversibilidade é algo tão discutido na filosofia da física 
quanto o problema da medição, com o qual está relacionado, de maneira que não tentaremos esclarecer sua natureza (vale dizer que algumas abordagens consideram que o evento macroscópico teria uma probabilidade ínfima mas finita de se desfazer e retornar à situação anterior à detecção) (ver Sklar 1993).

Em nossa análise até aqui, há uma certa ambiguidade com relação a se o evento de tipo (I) é microscópico ou macroscópico. Nas apresentações usuais da teoria da medição em mecânica quântica, haveria um evento microscópico (por exemplo, a ionização e acúmulo inicial de cargas em um local específico de uma chapa fotográfica, ocorrido após o processo de decoerência) seguido deterministicamente da formação de um evento macroscópico (após a amplificação propiciada pelos reagentes químicos na chapa fotográfica). O surgimento do evento microscópico é imprevisível, mas uma vez instaurado, a formação da versão macroscópica ocorre deterministicamente. Nessa situação, o evento elementar é claramente o evento microscópico, ocorrido após o colapso da onda quântica (em sua interação com a placa detectora).

\section{Processos quânticos reversíveis não envolveriam "eventos" causais}

A discussão anterior pressupõe que a mera propagação de uma entidade quântica no espaço (como as ondas circulares na Fig. 1) é um "processo" causal, mas que não envolve "eventos" causais. Isso está relacionado ao fato de que um sistema quântico fechado é "reversível".

A reversibilidade é uma propriedade de sistemas físicos cujas leis são invariantes ante mudança de sinal do tempo. Como exemplo na Mecânica Clássica, considere um sistema de bolas de bilhar que obedeçam às leis do choque elástico (Fig. 2). Após evoluir deterministicamente a partir de um estado inicial, por um tempo $\Delta t=$ $t_{1}-t_{0}$, imagine que se possa inverter instantânea e simultaneamente os vetores velocidade de todas as bolas de bilhar. Deixando este sistema evoluir pelo mesmo intervalo $\Delta t$, efetue novamente a inversão dos vetores velocidade de todas as bolas. Se retornarmos exatamente ao estado inicial, o sistema é reversível.

Um exemplo de sistema irreversível são as bolas de bilhar sobre uma mesa com atrito. Aplicando o procedimento descrito acima, não se retorna ao estado inicial, dado que a energia cinética das bolas é dissipada de maneira constante.Um evento de detecção quântica também é tomado como um processo irreversível. O que se dissipa no aparelho de medição e no ambiente é a coerência da onda quântica, que se perde em "defasagens aleatórias".

Consideramos que em um sistema quântico reversível não ocorram "eventos" propriamente ditos, salvo nos atos de confinamento (ver seção seguinte). A propagação de uma entidade quântica no espaço, ou seu confinamento no interior de

Principia 17(3): 365-381 (2013). 


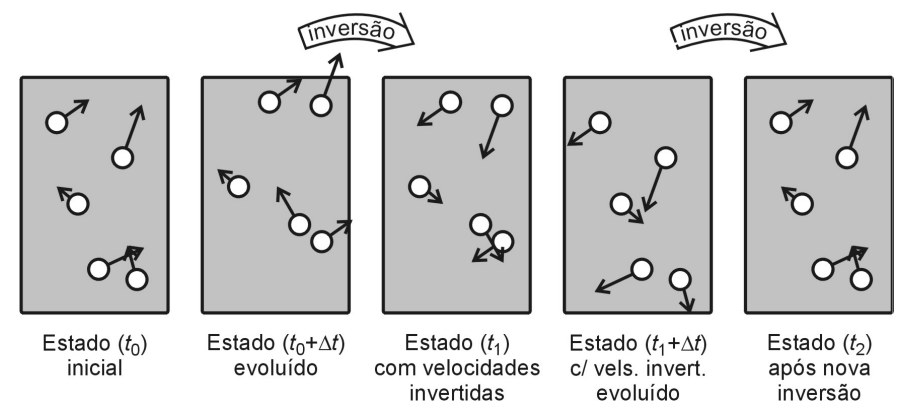

Figura 2: Duas inversões de velocidade separadas pelo mesmo intervalo $\Delta t=t_{1}-t_{0}$ levam o sistema de volta ao estado inicial, no caso de sistemas reversíveis.

uma molécula isolada, seria algo como um processo de escoamento, que pode ser chamado de um "processo causal" contínuo (Dowe 2009), e mesmo "determinista". A este processo de propagação Bohr (1934, p.54) chamou de "asserção da causalidade".

A discussão sobre o determinismo na filosofia da física contemporânea não tem trazido novidades, já que mesmo na física quântica não há uma posição consensual sobre se a natureza é fundamentalmente determinista ou não. Outra questão ainda sem solução, que surgiu na física quântica mais contemporânea, é se os processos físicos anteriores aos atos de preparação e medição de entidades quânticas são processos locais ou "não-locais" (envolvendo "ação à distância", ou propagação de informação a velocidades maiores do que a da luz). A descrição física do que ocorre entre os eventos de emissão e detecção de um quantum é um problema filosófico interessantíssimo, mas na medida em que ele se encontra além do domínio de manipulação humano (sendo abordado apenas de maneira teórica), propomos que o termo "evento causal" não seja aplicado a esses processos.

\section{Confinamento macroscópico}

Apesar de o processo de propagação livre de uma entidade quântica não envolver "eventos" (no mesmo sentido que o movimento inercial de uma partícula clássica livre não envolveria), a presença de certos dispositivos macroscópicos pode alterar o estado quântico do sistema (de maneira análoga a uma força conservativa que altera o movimento da partícula clássica).

A ação de tais dispositivos, que confinam de alguma maneira o sistema quântico sem que informação seja dele extraída, é descrita matematicamente por "operadores unitários" e são os responsáveis pela implementação das portas lógicas reversíveis na 
computação quântica. Tais operações claramente satisfazem o critério de intervenção ou manipulação associado ao conceito cotidiano de causalidade.

No experimento da fenda dupla da Fig. 1, quando um elétron passa pelo anteparo contendo as duas fendas, será que ele transfere momento linear (quantidade de movimento) para o anteparo, na direção paralela ao anteparo? O célebre debate entre Bohr e Einstein no Congresso de Solvay de 1927 concluiu que se tal transferência pudesse ser medida no anteparo, as franjas de interferência acabariam sendo borradas, após a incidência de um grande número de quanta. Bohr argumentou a partir do princípio de incerteza, mas há um conceito mais fácil de articular que é o de um "estado coerente de Glauber".

Tal estado quântico tem a propriedade de que a absorção ou perda de um quantum de energia deixa o sistema exatamente no mesmo estado! Roy Glauber redescobriu esses estados na década de 1960 (antes disso, Schrödinger os encontrara em 1926), ao estudar a descrição quântica do raio laser, que possui essa propriedade. No caso do laser, este estado é uma superposição infinita de autoestados com números diferentes de fótons, de tal forma que a aplicação do operador de aniquilamento de fóton a este estado gera o próprio estado. Outra maneira de exprimir isso é dizer que a incerteza da energia do laser é maior do que a energia perdida ou ganha com a troca de um fóton. O termo "estado coerente" foi dado porque é o estado que descreve um laser, mas já usamos o termo "coerência" em um sentido mais amplo: para não confundir os dois sentidos farei referência ao primeiro como "estado de Glauber".

Glauber comentou que esse comportamento é o que se esperaria de um corpo macroscópico clássico interagindo com um sistema quântico: um bastão de beisebol, em um estado de Glauber, acertando uma bolinha quântica, não sofreria nenhum rebote perceptível. Isso violaria, num certo sentido, o princípio de ação e reação da Mecânica Clássica. No entanto, apesar de a remoção de um único fóton não alterar o estado de um laser (pelo menos não de maneira detectável), a remoção de muitos fótons seria perceptível.

Veremos a seguir um exemplo que mostra a importância desses estados para explicar fenômenos quânticos corriqueiros de interferência, como o da Fig. 1.

\section{Experimento da dupla fenda com partículas correlacionadas}

Consideremos a emissão de um par de raios gama (uma forma energética de luz) a partir do aniquilamento de um par elétron-pósitron (Fig. 3) (Pessoa Jr. 2006, p.315). O estado deste par deve ser descrito por ondas esféricas, de tal forma que se uma partícula do par for detectada na fenda A da Fig. 3, a outra teria necessariamente o momento linear oposto, rumando na direção de X0. Analogamente, um fóton em B 


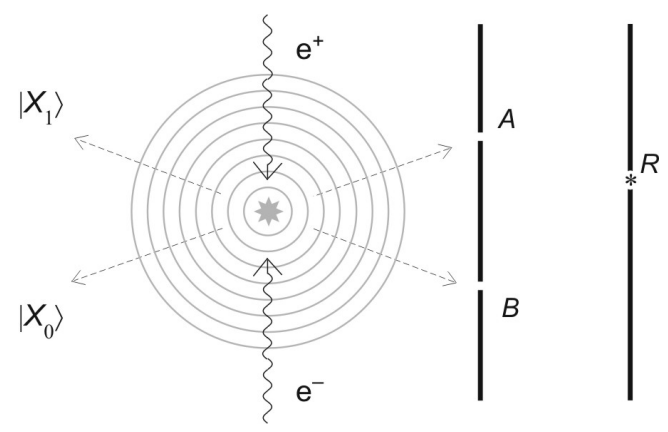

Figura 3: Um pósitron $e^{+}$e um elétron $e^{-}$se aniquilam, gerando um par de fótons de raio gama rumando na mesma direção, em sentidos opostos. Um dos fótons adentra a montagem do experimento da dupla fenda. Haverá padrão de interferência na tela detectora?

estaria correlacionado com o outro em X1. Neste experimento, coloca-se a pergunta: haverá padrão de interferência na tela à direita (para uma série de partículas preparadas da mesma maneira)?

A resposta é não. Uma maneira de raciocinar é considerar que os fótons que rumam para a esquerda carregam informação da trajetória da partícula que adentrou a montagem do experimento da dupla fenda. Pelo princípio de complementaridade, se houver informação de trajetória, não pode haver a formação de franjas de interferência.

\section{Exemplos de confinamento com os estados de Glauber}

Voltemos agora para o experimento da Fig. 1: se a informação de trajetória pudesse ser resgatada do movimento do anteparo na direção paralela a ele, pelo princípio de complementaridade não poderia haver a formação de padrão de interferência. Isso indica que o estado do anteparo, que contém as duas fendas, deve ser descrito como um estado coerente de Glauber, no qual a transferência de um quantum de momento não altera o seu estado!

Um exemplo mais claro ocorre na versão do experimento da fenda dupla para nêutrons (Fig. 4) (Badurek et al. 1983; Pessoa Jr. 2006, p.151-2). Colocando o experimento dentro de um campo magnético uniforme, o momento angular (spin) estará associado a energias diferentes se estiver apontado para cima ou para baixo. Pode-se inverter o momento angular em apenas uma das duas trajetórias do nêutron, antes da região de interferência, por meio de uma espira de rádio-frequência. Esta operação não borra o padrão de interferência! Será que é possível determinar 


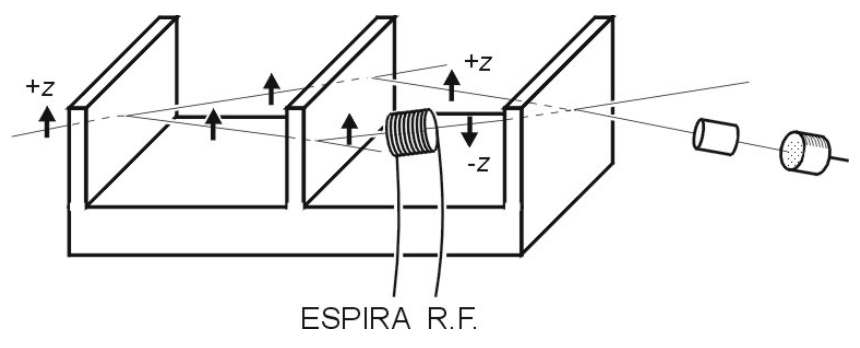

Figura 4: Interferômetro de nêutrons individuais, vindos da esquerda com componente de spin $+z$, difratados em três planos de um monocristal de silício. A espira RF inverte o spin do nêutron $(+z$ para $-z)$ em apenas um dos caminhos (alterando sua energia, pois todo o sistema está imerso em um campo magnético uniforme). A inversão do estado de spin mantém a coerência entre os componentes que interferem no plano final.

simultaneamente a trajetória do nêutron, inspecionando se a energia do campo de rádio-frequência aumentou ou diminuiu?

A resposta é não. Há a troca de um quantum de energia, com valor bem definido, mas tal absorção ou emissão por parte da espira não pode ser detectada, pois o seu campo de rádio-frequência está em um estado coerente de Glauber (Leggett 1986, p.40). Assim, não se obtém informação de trajetória, e a fase relativa dos componentes da onda neutrônica se mantém fixa (não há defasagens aleatórias). Em outras palavras, mesmo havendo a transferência de um quantum, tal transferência não constitui um evento causal do tipo (1).

Porém, há claramente uma alteração no estado do sistema neutrônico, detectável no padrão de absorção dos nêutrons durante a interferência. Assim, a ação da espira inversora de momento angular estabelece uma relação causal de confinamento, controlável pelo cientista, de tipo (2).

Outro exemplo bastante simples é a reflexão de um feixe de luz por um espelho, em um interferômetro como o de Mach-Zehnder (Pessoa Jr. 2006, cap. II). Há a transferência de momento do feixe de luz para o espelho, mas para um fóton único esta transferência de momento não altera o estado de Glauber associado ao espelho.

Em suma, nesta situação de tipo (2), o evento causal é perfeitamente controlável, mas os seus efeitos (os eventos de detecção posteriores) geralmente são imprevisíveis. Um cientista pode fazer uma manipulação e colocar detectores em uma região adequada do espaço, o que levará a eventos de tipo (1), mas os detalhes de ocorrência do evento (posição e instante) são incontroláveis. 


\section{Um terceiro tipo de evento causal: medições nulas}

Uma situação causal interessante ocorre na montagem de Elitzur-Vaidman (1993) (Fig. 5). Trata-se de um interferômetro de Mach-Zehnder com uma bomba sensível inserida no caminho B. Na ausência da bomba, todos os fótons são detectados em D1 (devido à interferência destrutiva em D2). Quando a bomba é inserida, para um único fóton incidente há uma probabilidade i de ela detonar.

Pode, porém, acontecer que o fóton seja detectado em D2. Esta é a situação interessante de ser analisada em termos causais. Segundo nossas definições, ocorre em D2 um evento causal de tipo (1), envolvendo amplificação.

Quanto à bomba, ela não se encontra em um estado de Glauber com relação à troca de fótons, pois pode absorver um fóton e explodir. Mesmo assim, no caso examinado (de detecção em D2), a bomba exerce um certo tipo de confinamento, e podemos dizer que a presença da bomba (um evento causal claramente manipulável) é uma das causas da detecção em D2.

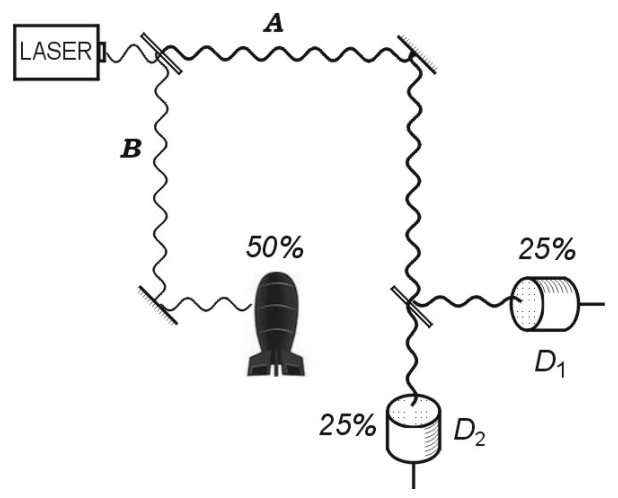

Figura 5: Interferômetro de Mach-Zehnder com uma bomba em um dos caminhos (Elitzur \& Vaidman, 1993).

Uma outra maneira de enfocar a montagem de Elitzur-Vaidman é considerar que a bomba, que é na verdade um aparelho de medição, realiza (nos casos em que não explode) uma medição de resultado nulo no sistema quântico (ver Pessoa Jr. 2006, $\breve{g}$ VIII.4). Em outras palavras, a não detonação da bomba fornece informação sobre o sistema, qual seja, que a luz rumou pelo caminho A; pode-se também dizer que ela provoca um "colapso" da onda quântica. Porém, ao contrário dos outros dois tipos de eventos quânticos, a medição nula ocorre sem uma troca líquida de fótons (no máximo há uma troca "virtual" de um par de fótons).

Principia 17(3): 365-381 (2013). 


\section{Discussão}

Enfocamos processos quânticos da escala espacial nanométrica, e buscando eventos manipuláveis por cientistas humanos, identificamos três tipos de eventos causais.

(1) O primeiro consiste da transferência de um quantum de energia para um sistema macroscópico, de tal forma que ocorre amplificação, e a informação do sistema nanoscópico torna-se acessível para o cientista. Tal processo envolve irreversibilidade e defasagens aleatórias nas ondas materiais quânticas envolvidas. O evento elementar é um evento microscópico no detector, ocorrido após o processo de decoerência da onda quântica medida, e seguido de maneira determinística pela amplificação do sinal, resultando em um evento macroscópico.

(2) O segundo tipo de evento causal envolve a manipulação e confinamento de sistemas quânticos sem destruir sua coerência (ou seja, sem introduzir fases aleatórias entre seus feixes componentes), com dispositivos macroscópicos descritos por meio de estados de Glauber. É esta a situação que ocorre com as portas lógicas reversíveis, que realizam operação unitárias sobre um sistema quântico, descritas na teoria da computação quântica. Nesse caso ocorre troca de um quantum de energia ou de momento, mas tal evento causal só é perceptível por seu efeito no sistema quântico, e não no equipamento macroscópico, que permanece no mesmo estado.

(3) A situação para eventos causais do terceiro tipo é análoga à situação de eventos de tipo (1). Uma medição de resultado nulo nada mais é do que uma medição em que não ocorreu a absorção de um quantum. No caso da bomba, na montagem de Elitzur-Vaidman, se ela explodir, teremos um evento de tipo (1); se ela não explodir, também podemos dizer que ela provocou "um colapso da onda quântica", constituindo um evento de tipo (3).

Os três tipos de eventos causais quânticos envolvem a interação de um cientista macroscópico com um sistema nanoscópico, separados por nove ordens de escala de grandeza. Já discutimos, porém, que é razoável supor (de acordo com interpretações objetivistas) que eventos quânticos possam ocorrer sem a presença de um cientista ou de um aparelho de medição, por exemplo no interior de uma célula biológica, o que envolveria separações menores de ordens de escala. Compreender essa espécie de processo intracelular é um desafio para o projeto reducionista, e esboçaremos alguns pontos desse projeto na seção seguinte.

Um comentário final deve ser dirigido à situação envolvendo pares de sistemas quânticos "emaranhados" e separados a grandes distâncias. O teorema de Bell estabeleceu que uma interpretação realista da teoria quântica deve envolver algum tipo de não-localidade, ou seja, a transmissão de algum tipo de informação a velocidades maiores do que a da luz.

Neste trabalho estamos adotando uma interpretação "objetivista”, segundo a qual a teoria quântica funciona mesmo sem a presença de seres conscientes. Uma 
interpretação "realista" é aquela que atribui realidade para os processos que ocorrem entre os eventos de preparação (ou confinamento) e medição, que acima chamamos de processos "causais" reversíveis, de escoamento de algum fluido, sem a ocorrência de "eventos" propriamente ditos. Seriam esses processos, frequentemente associados a uma onda quântica sujeita a colapsos, que não estariam restritos pela condição de localidade (em uma interpretação realista).

Já os três tipos de eventos apresentados neste trabalho estão sujeitos à condição de localidade. Ou seja, se há entre dois eventos uma relação de causa e efeito, certamente eles não têm separação de tipo espaço (usando a linguagem da teoria da relatividade restrita), e podem ser conectados por um sinal que se propaga a uma velocidade menor ou igual à da luz. No caso de pares de partículas emaranhadas, os eventos de medição em cada uma delas (com separação tipo espaço) não constituem uma relação causal (no sentido utilizado neste trabalho, envolvendo eventos até certo ponto manipuláveis, como nos três tipos de eventos examinados). Porém, nas interpretações realistas, deve-se atribuir aos processos de escoamento causal subjacentes alguma espécie de não-localidade.

\section{Continuidade do trabalho: motores moleculares}

O próximo passo do presente projeto será procurar identificar os três tipos de eventos causais vistos neste trabalho (e eventualmente outros) em uma situação prática da biologia molecular. O estudo de caso a ser considerado é o do motor molecular (Spudich 2006), presente no interior das células e associado ao transporte de substâncias ao longo de trilhos feitos de proteínas, como os microtúbulos. A Fig. 6 é um desenho esquemático de duas moléculas de dineína, que se locomovem em um microtúbulo citoplasmático, carregando outras proteínas e participando da divisão cromossômica. Visto de fora, o par de moléculas pode ser considerado um sistema clássico, pois sua tendência a entrar em superposições quânticas espaciais é suprimida pela interação com o meio circundante. As moléculas estão sujeitas a vibrações e torções internas, e estando imersas em banho aquoso, recebem o choque de um número imenso de moléculas de água por segundo, o que as fazem girar e se mover estocasticamente, em movimento browniano (Astumian 1997).

O problema a ser examinado na continuidade deste trabalho é entender os eventos causais que estão presentes no movimento do motor molecular.

(1) O movimento browniano da macromolécula pode ser reduzido ao conjunto de choques individuais com moléculas de água. Este movimento fornece energia para a molécula explorar a região a ela acessível, no meio viscoso. Porém, como entender os eventos de choque com as moléculas de água? Para isso, podemos estudar o que se sabe sobre o comportamento da água e o estabelecimento de pontes de hidrogênio.

Principia 17(3): 365-381 (2013). 


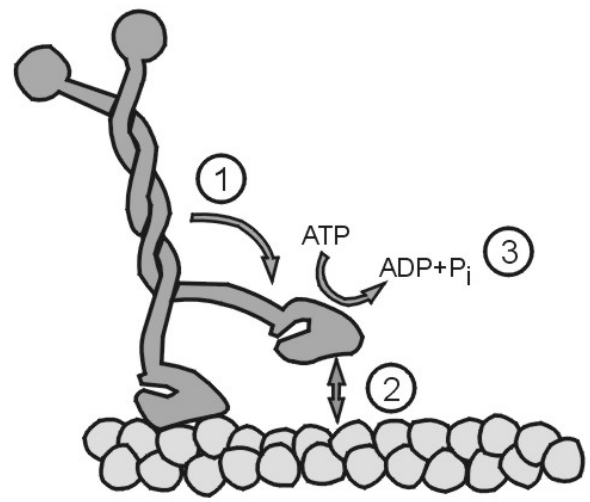

Figura 6: Dímero de dineína locomovendo-se em um microtúbulo. (1) Geração de movimento mecânico por movimento browniano. (2) Ligação ao microtúbulo. (3) Ligação e hidrólise de ATP, desprendendo o outro pé (adaptado de Spudich, 2006).

(2) O movimento estocástico da molécula, presa por um dos pés ao trilho, acaba levando o outro pé a se encaixar no microtúbulo, em uma interação eletrostática semelhante ao encaixe de uma chave em uma fechadura. Como entender este evento de adesão?

(3) Para ser possível a ação do motor molecular, é essencial a conversão ocasional de ATP em ADP, com a liberação de um quantum de energia, o que leva a uma mudança na conformação do par de moléculas e à liberação do outro pé. Este processo parece se encaixar no tipo (1) de eventos causais, descrito acima. A compreensão da termodinâmica dos motores moleculares é um resultado recente da biofísica (Astumian 1997). No geral, a molécula acaba flutuando para a direita e para esquerda, mas na média acaba tendo um deslocamento líquido para a direita.

Há de se considerar também a função biológica exercida pelo motor, o que envolve causas remotas associadas à seleção natural.

\section{Agradecimentos}

O projeto de investigar a causalidade em sistemas biológicos, do qual este é o primeiro passo, foi estimulado pelos desafios lançados por Gustavo Caponi e Charbel Niño El-Hani.

\section{References}

Anderson, P. W. 1972. More is Different. Science 177: 393-96.

Astumian, R. D. 1997. Thermodynamics and Kinetics of a Brownian Motor. Science 276: 917-22. 
Badurek, G.; Rauch, H.; Summhammer, J. 1983. Time-dependent Superpositions of Spinors. Physical Review Letters 51: 1015-18.

Benton, T. G.; Plaistow, S. J.; Coulson, T. N. 2006. Complex population dynamics and complex causation: devils, details and demography. Proceedings of the Royal Society B: Biological Sciences 273: 1173-81.

Bohr, N. 1934. The Quantum Postulate and the Recent Development of Atomic Theory. In: Bohr, N., Atomic Theory and the Description of Nature. Cambridge: Cambridge University Press, p.52-91. Tradução para o português em Pessoa Jr., O. (org.) (2000). Fundamentos da Física 1 - Simpósio David Bohm. São Paulo: Livraria da Física, p.135-59.

Caponi, G. 2009. Desarrollo, Causas Remotas e Historia Natural. Principia 13: 29-50.

Dowe, P. 2009. Causal Processes. Stanford Encyclopedia of Philosophy. Online: http://plato.stanford.edu/entries/causation-process.

El-Hani, C. N.; Queiroz, J. 2005. Downward Determination. Abstracta 1: 162-92.

Elitzur, A. C.; Vaidman, L. 1993. Quantum Mechanical Interaction-free Measurements. Foundations of Physics 23: 987-97.

Hume, D. 1740. An Abstract of a Book lately Published; Entitled, A Treatise of Human Nature. Online:

http://web.mnstate.edu/gracyk/courses/web\%20publishing/hume'sabstract.htm.

Leggett, A. J. 1986. Quantum Mechanics at the Macroscopic Level. In: de Boer, J.; Dal, E. \& Ulfbeck, O. (orgs.). The Lesson of Quantum Theory. Amsterdam: Elsevier, p.35-57.

Leibniz, G. W. 1902. XVII. Leibniz to Arnauld, Göttingen, April 30, 1687. In: Discourse on Metaphysics, Correspondence with Arnauld, and Monadology. Trad. G.R. Montgomery. La Salle (IL): Open Court, p.180-99.

Libet, B. 1999. Do We Have Free Will? Journal of Consciousness Studies 6: 47-57.

Mayr, E. 1961. Cause and Effect in Biology. Science 134: 1501-6.

Mill, J. S. 1843. System of Logic, vol. 1. Londres: John Parker. (Trad. parcial para o português: "Sistema de Lógica Dedutiva e Indutiva", in Os Pensadores, trad. J. M. Coelho, São Paulo: Abril Cultural, 1979.)

Noble, D. 2012. A Theory of Biological Relativity: No Privileged Level of Causation. Interface Focus 2: 55-64.

Pearl, J. 2000. Causality: Models, reasoning, and inference. Cambridge: Cambridge University Press.

Pessoa Jr., O. 1998. Can the Decoherence Approach Help to Solve the Measurement Problem? Synthese 113: 323-46.

- 2006. Conceitos de Física Quântica. Vols. 1, 2. São Paulo: Livraria da Física.

—. 2007. Redução de Estado na Física Quântica: Amplificação ou Consciência? In: Lorenzano, P.; Miguel, H. (orgs.). Filosofía e Historia de la Ciencia en el Cono Sur. Vol. II, Buenos Aires: AFHIC-Educando, pp. 451-60.

Polanyi, M. 1968. Life's Irreducible Structure. Science 160: 1308-12.

Primas, H. 1990. Induced Nonlinear Time Evolution of Open Quantum Objects. In: Miller, A. I. (org.) Sixty-two Years of Uncertainty. New York: Plenum, pp. 259-80.

Schlosshauer, M. 2004. Decoherence, the Measurement Problem, and Interpretations of Quantum Mechanics. Reviews of Modern Physics 76: 1267-305.

Sklar, L. 1993. Physics and Chance: Philosophical issues in the foundations of statistical mechanics. Cambridge: Cambridge University Press. 
Spudich, J. A. 2006. Molecular Motors take Tension in Stride. Cell 126: 242-4.

Westerhoff, H. V.; Hofmeyr, J.-H. S. 2005. What is Systems Biology? From genes to function and back. In: Alberghina, L.; Westerhoff, H.V. (eds.) Systems Biology: Definitions and perspectives. Berlin: Springer, p.119-41.

Wilson, D. S. 1997. Altruism and Organism: Disentangling the themes of multilevel selection theory. American Naturalist 150: S122-S134.

Woodward, J. 2008. Causation and Manipulability. Stanford Encyclopedia of Philosophy. Online: http://plato.stanford.edu/entries/causation-mani.

\author{
Osvaldo Pessoa Jr. \\ Depto. Filosofia - FFLCH \\ Universidade de São Paulo \\ Av. Prof. Luciano Gualberto, 315 \\ 05508-900 São Paulo, SP \\ BRASIL \\ opessoa@usp.br
}

Resumo. Este trabalho é o primeiro passo na investigação de se eventos microscópicos podem ser reduzidos a uma composição mereológica de eventos elementares, especialmente em sistemas biológicos. Parte-se da hipótese de que entre eventos de transferência de quanta ocorre escoamento causal, mas não ocorrem eventos propriamente ditos. Um evento causal é caracterizado pela possibilidade de uma intervenção ou manipulação. Assim, encontram-se três tipos de eventos quânticos: (1) detecção de um quantum de energia; (2) confinamento por aparelho em um estado coerente de Glauber; (3) medição de resultado nulo (sem transferência líquida de quanta). Este trabalho explora esses três tipos de eventos causais elementares, e coloca como passo seguinte a investigação de eventos causais envolvidos na ação de um motor molecular.

Palavras-chave: Mecânica quântica; causalidade; evento; reducionismo; motor molecular.

Principia 17(3): 365-381 (2013). 